\title{
Furosemide Pharmacodynamics and Cardiovascular Effects in Hemodialysis Patients
}

\author{
NICOLAE ALBULESCU1", ADRIAN APOSTOL ${ }^{1 \#, ~ I U L I A N A ~ R O X A N A ~ A L B U L E S C U ², ~ A D E L I N A ~ M I H A E S C U 3 *, ~ A D A L B E R T ~ S C H I L L E R ~}{ }^{3}$, \\ ROMULUS TIMAR ${ }^{4}$ \\ ${ }^{1}$ Victor Babes University of Medicine and Pharmacy, Department of Cardiology, County Emergency Hospital Pius Brinzeu \\ Timisoara, 2 Eftimie Murgu Sq., 300041, Timisoara, Romania \\ 2 Victor Babes University of Medicine and Pharmacy, 2 Eftimie Murgu Sq., 300041, Timisoara, Romania. \\ ${ }^{3}$ Victor Babes University of Medicine and Pharmacy, Department of Nephrology, Emergency County Hospital Pius Brinzeu, \\ 2 Eftimie Murgu Sq., 30004, Timisoara, Romania \\ Hospital Pius Brinzeu Timisoara, 2 Eftimie Murgu Sq., 300041,Timisoara, Romania
}

\begin{abstract}
${ }^{4}$ Victor Babes University of Medicine and Pharmacy,Department of Diabetes and Metabolic Diseases, Emergency County
Furosemide is a drug that has not only a renal effect, but also a vascular one, resulting in decreased left atrial and ventricularfilling pressure accompanied by an increase in venous compliance, all of this with significant effects on central cardiac hemodynamics. In dialysis patients, it is still unclear the efficiency of furosemide, a diuretic drug that inhibits the $\mathrm{Na}+, \mathrm{K}+, 2 \mathrm{Cl}$ " cotransporter in the renal tubular system. Also, furosemide need to be used at much higher doses because of its pharmacokinetic changes in the context of impaired renal clearance.The aim of our study was to investigate whether furosemide induces changes in cardiovascular hemodynamics in end-stage renal disease (ESRD) patients, using standard echocardiography and Tissue Doppler Imaging (TDI).We foundcorrelations between furosemide useand improved cardiac parameters, assessed by multiple echocardiographic variables, and we consider that furosemide has complementary effects in dialysis patients with residual diuresis.
\end{abstract}

Keywords: furosemide, dialysis residualdiuresis, hemodialysis diuretic

Diuretics are often stopped when patients start dialysis. Some studies have shown that preserved residual renal function in dialysis patients is associated with bettercardiovascular status and although the association between diuretic and preserved residual renal function is still in debating, the clinical and paraclinical benefits offered by furosemide make it valuable in dialysis patients with urine output [1-3].In dialysis patients, even with someresidual diuresis, furosemide has been shown to induce a rapid vascular effect, besides the diuretic effect. Venous dilatation occurs, and therefore a decrease in cardiac preload and filling pressures[1,2,4]. Several parameters, such as left ventricular hypertrophy $(\mathrm{LVH})$ and left ventricular (LV) systolic dysfunction, have been identified as independent outcome predictorsin dialysis patients [5-7]. Diastolic heart failure and increased filling pressures in dialysis patients often exists without the presence of significant systolic heart failure, and that may be assessed by Doppler techniques, especially Tissue Doppler Imaging (TDI), that has also demonstrated its significant prognostic value for all-cause mortality and cardiovascular death [8-10]. Novel Doppler techniques should be able to detect even more subtle changes in cardiac function induced by furosemide $[2,8-11]$,

E-wave velocity reflects the left atrium $(L A)$-left ventricle( LV) pressure gradient during early diastole filling and is affected by impaired LV relaxation andleft atrial pressure(LAP)[8,9].A-wave velocity reflects the LA-LV pressure gradient during late diastole, and it depends by LV compliance and LA contractile function.Mitral E-velocity deceleration time(DT) is influenced by LV relaxation, LV diastolic pressures after mitral valve opening, and left ventricular stiffness.Isovolumetric relaxation time(IVRT) is prolonged in patients with impaired LV relaxation but normal LV filling pressures. When LAP increases, IVRTduration shortens and being inversely corelated with $\mathrm{LV}$ filling pressures. $[8,9] \mathrm{LA}$ volume index( $\mathrm{LAVi}$ ) reflects the cumulative effects of increased LV filling pressures and increased LAVi is an independent predictor of death, heart failure, atrial fibrillation, and ischemic stroke.CW Doppler tricuspid regurgitation(CWTR) systolic jet velocitysignificant correlation exists between systolic pulmonary artery pressure(SPAP) and noninvasively derived LAP. Increased SPAP suggests elevated LAP, if pulmonary disease is absent $[9,10]$.E/E'velocity has a powerful correlation with pulmonary capillary wedge pressure (PCWP) compared with invasive measurements of LV filling pressure.Mitral E velocity obtained byPW Doppler complemented using E/e' ratio correlates well to the mean pulmonary capillary wedge pressure (PCWP) as obtained by simultaneous catheter measurements $[10,12]$. E/E' ratio is a marker of left atrial filling pressure. $[9,10,12]$

\section{Experimental part}

\section{Materials and method}

We selected for our study, between J anuary 2015 to December 2016, ESRD patients, who were treated with HD three times a week for more than 6 months, in whom there were some residual diuresis ( 250 to $650 \mathrm{~mL}$ urine/ day). We chose the patients in sinus rhythm, without severe valvular heart disease, ischemic heart disease, congestive heart failure (NYHAclasses III and IV), pulmonary disease or significant pericardial disease.Conventional twodimensional echocardiography and TDI were recorded with a Siemens Acuson P300, immediately before the dialysis session, therefore cardiac hemodynamics not being influenced by volume or speed ultrafiltration. The echo report was recorded at baseline and further after in similar 


\begin{tabular}{|c|c|c|c|}
\hline VARIABLE & $\begin{array}{l}\text { CONTROL } \\
\text { GROUP }(\mathrm{N}=54)\end{array}$ & $\begin{array}{l}\text { FUROSEMIDE } \\
\text { GROUP }(\mathrm{N}=47)\end{array}$ & $\mathrm{P}$ \\
\hline MALE GENDER, N (\%) & $38(70,37 \%)$ & $31(65.95 \%)$ & NS \\
\hline$A G E, Y E A R S(M E A N \pm S D)$ & $57,21 \pm 6.92$ & $54,62 \pm 8.81$ & NS \\
\hline ETIOLOGY OF RENAL FAILURE, N (\%) & & & $\mathrm{NS}$ \\
\hline DIABETES MELLITUS & $21(38.88 \%)$ & $16(34.04 \%)$ & $\overline{N S}$ \\
\hline ARTERIAL HYPERTENSION/RENOVASCULAR & $17(31.48 \%)$ & $14(29.78 \%)$ & $\mathrm{NS}^{-}$ \\
\hline GLOMERULONEPHRITIS & $12(22.22 \%)$ & $8(17.02 \%)$ & $\mathrm{NS}^{-}$ \\
\hline OBSTRUCTIVE/REFLUX & $7(12.96 \%)$ & $5(10.63 \%)$ & NS \\
\hline POLYCYSTIC KIDNEY DISEASE & $2(3.70 \%)$ & $1(2.12 \%)$ & NS \\
\hline OTHER CAUSES & $5(9.25 \%)$ & $3(6.38)$ & NS \\
\hline DIALYSIS VINTAGE, YEARS (MEAN $\pm S D)$ & $2.6 \pm 1.7$ & $2.4 \pm 1.4$ & $\mathrm{NS}$ \\
\hline DAILY DIURESIS, ML (MEAN \pm SD) & $381.35 \pm 80.83$ & $561.36 \pm 65.12$ & $<.001$ \\
\hline FUROSEMIDE DOSE, MG (MEAN $\pm S D$ ) & 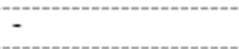 & $175.3 \pm 62.78$ & - \\
\hline AV FISTULA, $N(\%)$ & $42(77.77 \%)$ & $35(74.46 \%)$ & $\mathrm{NS}$ \\
\hline $\mathrm{BMI}, \mathrm{KG} / \mathrm{M}^{2}(\mathrm{MEAN} \pm \mathrm{SD})$ & $25.4 \pm 3.4$ & $25.5 \pm 4.9$ & $\overline{N S}$ \\
\hline BODY SURFACE AREA, M²(MEAN $\pm S D)$ & $1.85 \pm 0.35$ & $1.81 \pm 0.31$ & NS \\
\hline DISLYPIDEMIA, N (\%) & $24(44.44 \%)$ & $20(42.55 \%)$ & $\mathrm{NS}$ \\
\hline CIGARETTE SMOKING & $9(16.66 \%)$ & $8(17.02 \%)$ & $\mathrm{NSS}$ \\
\hline
\end{tabular}

conditions.All patientsbenefited from cardioprotective medications which hadshown to reduce mortality[13] in the general population such as angiotensinconverting enzyme inhibitors, beta-adrenergic antagonists (betablockers), acetylsalicylicacid,3-hydroxy-3-methyl-glutaryl coenzyme A reductase inhibitors (statins) and cytoprotective anti-ischemic agent [14].Dyslipidemia, measured through blood test, (including high levels of cholesterol, triglycerides, LDLC and low levels of HDLC) is part from thefactors involved in increased cardiovascular risk associated with CKD and also with progression of kidney failure [15]. Furthermore, the variety of biomarkers availabled for monitoring and for the prognosis of acute kidney injury(AKI) are limited, andin present numerous trials have proven the importance of microRNAs in this field[16,17].Standard echo measurements, including left ventricular end diastolic and end systolic dimensions (LVEDD and LVESD), end-diastolic and systolic wall thickness of interventricular septum (IVSd and IVSs) and left ventricular posterior wall (PWTD and PWTS) were determined with the M-mode (Mm) technique. Ejection fraction (EF) was determined using M mode and Simpson method and complemented by eyeballing.LV mass was calculated by Devereux's formula using the M-mode of the parasternal long axis view, and indexed to body surface area. LV hypertrophy was defined as LVMI $>115 \mathrm{~g} / \mathrm{m}^{2}$ in men and $>95 \mathrm{~g} / \mathrm{m}^{2}$ in women $[8,9]$. Left atrium dimension( $L A d$ ) was measured as anteroposterior diameter in $M$ mode from parasternal long axis view and also as left atrial volume using bidisc method in the apical four and two chamber view.

LV diastolic function parameters were assessed both conventional and through TDI. Using pulse-wave Doppler(PW) at the tip of the mitral leaflets in the 4chamber view, mitral E-wave velocity, E-wave deceleration time (DT), and late diastolic wave (A) velocity were measured. Mitral inflow E/A ratio and DT are used to identify the filling patterns: normal, impaired relaxation, pseudonormal, and restrictive filling [8,9].TDI wasperformed in high frame rate ( $\geq 100$ frames/second) from the apical four chamber view to assess myocardial velocities. Peak annular early diastolic velocity ( $E^{\prime}$ ) was measured in annular LV segments (septal and lateral). E/E2 ratio was calculated, and significant $\mathrm{LV}$ diastolic dysfunction was defined as $\mathrm{E} /$ $E^{\prime} \geq 14$, septal $E^{\prime}$ velocity $<7 \mathrm{~cm} / \mathrm{s}$, lateral $E^{\prime}$ velocity $<10$ $\mathrm{cm} / \mathrm{s}, C W$ TR velocity $>2.8 \mathrm{~m} / \mathrm{s}$ and $L A$ volume index $(\mathrm{LAVi})>34 \mathrm{~mL} / \mathrm{m}^{2}[8,9]$. E/E' ratio $<8$ isassociated with normal LV filling pressures (PCWP $<15 \mathrm{mmHg}$ ), while a ratio $>15$ is associated with increased filling pressures (PCWP > 15mmHg) [ 10,12,].

\section{Statistical analysis}

Statistical analysis was performed usingGraphPad Software, Inc 3.1. To calculate the statistical significance, we performed comparisons between the two groups using the t-Student test and Fisher exact test. For variables with Gaussian distribution, the values are presented as mean \pm standard deviation and $\mathrm{p}$ was calculated using unpaired $t-$ Student test. Correlation has been evaluated with Pearson test. Comparisons between baseline and next month measurements were performed using ANOVA with the Turkey post hoc test.Statistical significance was considered if $p<0.05$.

\section{Results and discussions}

No patient died or suffered from a major cardiovascular event. In table 1 we can see that there were no significant differences between the group characteristics (gender, age, etiology, dialysis period, vascular acces, BMI, BSA and the presence of other risk factors). There was a significantly better urine output in the furosemide group $(p<0.0001)$, proportionally correlated to a higher dose of furosemide. None of the patients had normal diastolic function and all of them had LVH withnormal EF(>55\%).Also, there were no differences between blood pressure values over time in both groups.All patients were examinated imediatly before dialysis, so they were overhydrated, which was demonstrated by high $E / E^{\prime}$ values, indicating a CPWP $>12$ $\mathrm{mmHg}\left(\mathrm{E} / \mathrm{E}^{\prime}>15\right)$. E wave, A wave, E/A ratio, DT, LA parameters and SPAP were higher in the control group and it got worse through time reaching statistical significance $(p<0.05)$ as seen in Table 2 . Regarding TDI parameters we observe in Table 3 that $E^{\prime}$ wave, $A^{\prime}$ wave, E/ $\mathrm{E}^{\prime}$ ratio are direct proportional, with high PCWP and LV filling pressures. Standard echocardiography and a more sensitive method, TDI, showed that furosemide was able to inducechanges in cardiac hemodynamics also correlated with urine output. Most of the echocardiographic parameters were significantly better in dialysis patients receiving furosemide, as evaluated through time. Furosemide can cause a rapid venodilatory response, which starts before an effect on diuresis and can be notedvia echo parameters $[2,18]$. Previous studies concerning cardiovascular effects of furosemide have shown different results, due to various methods, vascular status and studied 
Table 2

CLINICAL AND STANDARD ECHOCARDIOGRAPHY PARAMETERS IN THE STUDIED GROUP PATIENTS

\begin{tabular}{|c|c|c|c|c|c|c|c|c|c|}
\hline & Parameter & Baseline & 3 months & 6 months & 9 months & 12 months & 18 months & 24 months & $\mathrm{P}$ \\
\hline & $\mathrm{EF}(\%)$ & $61.1 \pm 11.0$ & $62.8 \pm 13.6$ & $61.3 \pm 12.5$ & $60.6 \pm 14.4$ & $58.9 \pm 15.6$ & $56.7 \pm 16.4$ & $57.1 \pm 18.5$ & NS \\
\hline & $\mathrm{FS}(\%)$ & $37.7 \pm 11.5$ & $37.1 \pm 13.2$ & $35.3 \pm 11.4$ & $36.6 \pm 12.2$ & $34.3 \pm 10.6$ & $33.5 \pm 13.1$ & $34.8 \pm 11.8$ & NS \\
\hline & $\mathrm{E}(\mathrm{m} / \mathrm{s})$ & $0.9 \pm 0.3$ & $1.2 \pm 0.5$ & $1.1 \pm 0.2$ & $0.8 \pm 0.4$ & $1.0 \pm 0.1$ & $1.1 \pm 0.4$ & $1.2 \pm 0.5$ & $<.001$ \\
\hline & $\mathrm{A}(\mathrm{m} / \mathrm{s})$ & $0.7 \pm 0.4$ & $0.9 \pm 0.2$ & $0.7 \pm 0.5$ & $0.9 \pm 0.2$ & $0.8 \pm 0.3$ & $0.6 \pm 0.5$ & $0.5 \pm 0.4$ & $<.0001$ \\
\hline & $\mathrm{E} / \mathrm{A}$ & $1.9 \pm 0.8$ & $1.8 \pm 1.1$ & $2.0 \pm 1.5$ & $2.2 \pm 1.8$ & $2.1 \pm 2.0$ & $1.9 \pm 1.4$ & $2.2 \pm 1.2$ & $<.0001$ \\
\hline Control & $\mathrm{DT}(\mathrm{ms})$ & $170.2 \pm 254$ & $174.9 \pm 29.6$ & $167.3 \pm 31.8$ & $181.4 \pm 413$ & $189.2 \pm 33.4$ & $193 \pm 392$ & $191.3 \pm 49.5$ & $<.0001$ \\
\hline group & $\mathrm{L} \mathrm{AV}(\mathrm{ml})$ & $68.1 \pm 17.5$ & $621 \pm 16.0$ & $76.5 \pm 26.2$ & $61.7 \pm 13.6$ & $88.8 \pm 19.4$ & $71.2 \pm 16.3$ & $80.3 \pm 29.2$ & $<.0001$ \\
\hline & $\mathrm{LAd}(\mathrm{cm})$ & $3.9 \pm 2.6$ & $4.2 \pm 1.8$ & $4.5 \pm 1.8$ & $4.7 \pm 2.7$ & $4.6 \pm 2.3$ & $4.4 \pm 2.5$ & $4.4 \pm 1.4$ & $<.0001$ \\
\hline & $\mathrm{CW}$ TR $(\mathrm{m} / \mathrm{s})$ & $2.4 \pm 0.6$ & $2.3 \pm 0.7$ & $2.6 \pm 0.5$ & $2.8 \pm 0.8$ & $2.9 \pm 0.7$ & $3.2 \pm 0.4$ & $3.3 \pm 0.5$ & $<.0001$ \\
\hline & $\overline{\mathrm{LVm}}(\mathrm{g})$ & $191.9 \pm 39.5$ & $186.5 \pm 26.8$ & $193.3 \pm 42.4$ & $195.5 \pm 47.1$ & $198.1 \pm 47.2$ & $198.6 \pm 39.8$ & $210.6 \pm 43.1$ & .0993 \\
\hline & $\mathrm{SBP}(\mathrm{mmHg})$ & $143.8 \pm 22.1$ & $150.0 \pm 18.2$ & $152.5 \pm 16.2$ & $133.5 \pm 74.3$ & $150.4 \pm 16.3$ & $148.0 \pm 14.3$ & $152.0 \pm 14.2$ & $\mathrm{NS}$ \\
\hline & $\mathrm{DBP}(\mathrm{mmHg})$ & $82.0 \pm 11.0$ & $81.0 \pm 9.7$ & $89.4 \pm 9.3$ & $79.5 \pm 9.8$ & $86.5 \pm 10.6$ & $87.0 \pm 9.6$ & $89.5 \pm 12.5$ & NS \\
\hline & $\mathrm{EF}(\%)$ & $62.1 \pm 11.6$ & $62.2 \pm 8.9$ & $64.3 \pm 10.7$ & $60.4 \pm 8.5$ & $60.1 \pm 18.6$ & $59.2 \pm 17.7$ & $59.4 \pm 12.3$ & NS \\
\hline & $\mathrm{FS}(\%)$ & $38.2 \pm 11.8$ & $39.4 \pm 9.4$ & $38.1 \pm 9.7$ & $37.8 \pm 8.9$ & $36.2 \pm 11.5$ & $35.7 \pm 10.1$ & $35.5 \pm 5.0$ & $\mathrm{NS}$ \\
\hline & $\mathrm{E}(\mathrm{m} / \mathrm{s})$ & $0.7 \pm 0.3$ & $0.9 \pm 0.2$ & $0.8 \pm 0.4$ & $1.1 \pm 0.2$ & $0.9 \pm 0.2$ & $0.9 \pm 0.3$ & $1.0 \pm 0.1$ & .0005 \\
\hline & $\mathrm{A}(\mathrm{m} / \mathrm{s})$ & $0.7 \pm 0.2$ & $0.8 \pm 0.3$ & $0.6 \pm 0.2$ & $0.6 \pm 0.3$ & $0.8 \pm 0.2$ & $0.8 \pm 0.4$ & $0.9 \pm 0.1$ & .005 \\
\hline & $\mathrm{E} / \mathrm{A}$ & $1.1 \pm 0.3$ & $1.4 \pm 0.5$ & $1.3 \pm 0.6$ & $1.4 \pm 0.7$ & $1.3 \pm 0.6$ & $1.0 \pm 0.4$ & $1.4 \pm 0.7$ & $.003 \overline{1}$ \\
\hline Furogemide & $\mathrm{DT}(\mathrm{ms})$ & $164.2+23.4$ & $184.9 \pm 29.6$ & $187.3 \pm 31.8$ & $191.4 \pm 413$ & $169.2 \pm 53.4$ & $173 \pm 49.2$ & $181.3 \pm 49.5$ & .0318 \\
\hline group & $\mathrm{LAV}(\mathrm{ml})$ & $58.1 \pm 17.5$ & $62.1 \pm 16.0$ & $56.5 \pm 16.2$ & $61.7 \pm 13.6$ & $58.8 \pm 19.4$ & $61.2 \pm 16.3$ & $60.3 \pm 19.2$ & NS \\
\hline & $\mathrm{LAd}(\mathrm{cm})$ & $2.9 \pm 1.1$ & $3.3 \pm 1.9$ & $3.5 \pm 1.6$ & $4.8 \pm 2.0$ & $3.7 \pm 1.4$ & $3.5 \pm 1.6$ & $3.9 \pm 1.1$ & $<.001$ \\
\hline & $\mathrm{CW} \mathrm{TR}(\mathrm{m} / \mathrm{s})$ & $2.0 \pm 0.6$ & $2.0 \pm 0.7$ & $2.4 \pm 0.5$ & $2.7 \pm 0.8$ & $2.6 \pm 0.7$ & $2.8 \pm 0.4$ & $3.0 \pm 0.5$ & $<.0001$ \\
\hline & $\mathrm{LVm}(g)$ & $181.9 \pm 35.5$ & $176.6 \pm 29.6$ & $190.3 \pm 43.2$ & $185.5 \pm 48.4$ & $199.1 \pm 37.2$ & $189 \pm 29.8$ & $201 \pm 48.6$ & .0545 \\
\hline & $\mathrm{SBP}(\mathrm{mmHg})$ & $143.3 \pm 20.5$ & $147.5 \pm 22.2$ & $143.7 \pm 26.9$ & $145.8 \pm 24.0$ & $144.2 \pm 21.5$ & $143.8 \pm 20.1$ & $141.8 \pm 22.8$ & $\mathrm{NS}^{-}$ \\
\hline & $\mathrm{DBP}(\mathrm{mmHg})$ & $76.2 \pm 7.5$ & $70.0 \pm 11.5$ & $78.7 \pm 10.3$ & $73.7 \pm 13.8$ & $79.7 \pm 14.9$ & $73.7 \pm 14.9$ & $77.9 \pm 17.9$ & $\mathrm{NS}$ \\
\hline
\end{tabular}

Table 3

TDI PARAMETERS OF LV DIASTOLIC FUNCTION AND LV FILLING PRESSURE IN STUDIED GROUPS. PCW P WAS ESTIMATED USING NAGUEH FORMULA (PCWP $\left.=1.24 *\left(E / E^{\prime}\right)+1.9\right)$

\begin{tabular}{|c|c|c|c|c|c|c|c|c|c|}
\hline & Parameter & Baseline & 3 months & 6 months & 9 months & 12 months & 18 months & 24 months & $\mathrm{P}$ \\
\hline & $\mathrm{E}^{\prime}(\mathrm{cm} / \mathrm{s})$ & $5.8 \pm 1.4$ & $6.3 \pm 1.6$ & $5.9 \pm 1.5$ & $5.9 \pm 1.7$ & $7.1 \pm 1.8$ & $6.4 \pm 1.6$ & $7.2 \pm 1.7$ & $<.0001$ \\
\hline & $\mathrm{A}^{\prime}(\mathrm{cm} / \mathrm{s})$ & $5.0 \pm 2.4$ & $4.6 \pm 2.3$ & $4.7 \pm 1.9$ & $5.1 \pm 1.8$ & $5.6 \pm 2.0$ & $5.5 \pm 2.1$ & $6.5 \pm 2.2$ & $<.001$ \\
\hline Control & $\mathrm{E}^{\prime} / \mathrm{A}^{--}$ & $0.9 \pm 0.4$ & $1.7 \pm 1.2$ & $1.5 \pm 0.8$ & $2.0 \pm 0.5$ & $1.4 \pm 0.7$ & $1.6 \pm 1.0$ & $1.5 \pm 0.5$ & $<.0001$ \\
\hline \multirow[t]{5}{*}{ group } & $\mathrm{E} / \mathrm{E}^{-}$ & $21.1 \pm 18.8$ & $28.8 \pm 13.3$ & $22.0 \pm 14.5$ & $26.1 \pm 14.2$ & $36.0 \pm 16.8$ & $31.3 \pm 8.1$ & $32.9 \pm 18.2$ & $<.0001$ \\
\hline & $\begin{array}{l}\text { IVRT } \\
(\mathrm{ms})\end{array}$ & $108.9 \pm 32.5$ & $95.6 \pm 24.2$ & $93.5 \pm 23.8$ & $104.2 \pm 33.3$ & $109.5 \pm 19.3$ & $107.1 \pm 21.4$ & $111.4 \pm 28.8$ & $<.0011$ \\
\hline & $\begin{array}{l}\text { ePCWP } \\
(\mathrm{mmHg})\end{array}$ & $15.8 \pm 2.7$ & $13.9 \pm 1.8$ & $16.8 \pm 2.6$ & $17.9 \pm 2.3$ & $15.4 \pm 2.1$ & $14.1 \pm 2.9$ & $18.2 \pm 3.4$ & $<.0001$ \\
\hline & $\mathrm{E}^{\prime}(\mathrm{m} / \mathrm{s})$ & $4.8 \pm 1.9$ & $4.5 \pm 2.3$ & $5.1 \pm 2.1$ & $4.9 \pm 1.8$ & $4.7 \pm 2.3$ & $4.7 \pm 1.3$ & $5.7 \pm 2.3$ & $<.0001$ \\
\hline & $\mathrm{A}^{\prime}(\mathrm{m} / \mathrm{s})$ & $6.4 \pm 1.2$ & $5.5 \pm 1.5$ & $5.8 \pm 1.7$ & $5.7 \pm 1.5$ & $6.1 \pm 1.8$ & $7.1 \pm 1.8$ & $6.6 \pm 1.8$ & $<.05$ \\
\hline Furosemide & $\mathrm{E} / \mathrm{A}$ & $0.8 \pm 0.4$ & $0.7 \pm 0.3$ & $0.9 \pm 0.5$ & $0.9 \pm 0.2$ & $1.1 \pm 0.3$ & $0.8 \pm 0.3$ & $1.2 \pm 0.4$ & $\mathrm{NS}$ \\
\hline \multirow[t]{3}{*}{ group } & $\mathrm{E} / \mathrm{E}^{\prime}$ & $17.5 \pm 7.5$ & $22.2 \pm 7.6$ & $24.0 \pm 12.9$ & $25.4 \pm 11.9$ & $26.3 \pm 15.6$ & $19.0 \pm 4.9$ & $20.1 \pm 6.2$ & $<.0001$ \\
\hline & $\begin{array}{l}\text { IVRT } \\
(\mathrm{ms})\end{array}$ & $122.6 \pm 41.2$ & $118.9 \pm 32.3$ & $124.3 \pm 36.9$ & $115.4 \pm 32.2$ & $121.0 \pm 44.7$ & $117.0 \pm 34.4$ & $119.0 \pm 24.0$ & $<0.01$ \\
\hline & $\begin{array}{l}\text { ePCWP } \\
(\mathrm{mmHg})\end{array}$ & $11.7 \pm 1.6$ & $12.9 \pm 2.3$ & $10.4 \pm 1.6$ & $13.9 \pm 2.5$ & $14.0 \pm 2.1$ & $13.1 \pm 3.2$ & $13.2 \pm 2.6$ & $<.0001$ \\
\hline
\end{tabular}

Abbreviations: $E F=$ Ejection traction, $F S=$ Fractional shortening, $E=$ Early distolic flow velocity, $A=$ Late diastolic flow (atrial kick), DT =Mitral Evelocity deceleration time, $L A V=$ left atrial volume, $L A d=$ left atrial antero-posterior diameter, $C W$ TR=continuous wave Doppler tricuspid regurgitation velocity, $S B P / D B P=$ systolic/diastolic blood pressure, $E^{\prime}=$ Average of the lateral and septal $E^{\prime}$ values, IVRT=isovolumetric relaxation time, $e P C W P=$ estimated pulmonary capillary wedge pressure.

populations. Some studies have suggested that furosemide also has extra renal effects, some vascular effects that may justify its use also in anuric patients [2,19]. However, studies evaluating the vascular effects of furosemide in ESRD patients have shown conflicting results. Schmieder published a study in wichan iv bolus of furosemide wasgiven to HD patients [20]. The result was a significant decrease in central blood volume that was seen minutes after the bolus, indicating a redistribution of blood from the cardiopulmonary system to the periphery [20]. Other authors demonstrated that after an intravenous dose of furosemide left ventricular fillingpressure decreased. It's important to understand that there is much more to an echo exam than mere EF [5]. eGFR value alone- demonstrated that is a better follow-up parameter then EF, as a marker for cardiovascular morbidity and mortality [21].So, in this special population we have to come with something more in orderto add more prognostic value. The novel tissue Doppler and Speckle tracking techniques can guide us to understand and treat the complex patient involved in this pathophysiological relation between kidney and heart [8-12].Also, in most studies, arterial stiffness is assessed by carotid-femural pulse wave velocity (cfPWV), andwould have been a useful markerbecause it is correlated with overall mortality and cardiovascular mortality,even in dialysis patients [22]. Furthermore, we emphasise the need for more large-scale randomized studies in dialysis patients and comprehensive cardiovascular guidelines for their management $[2,23]$. 


\section{Conclusions}

The aim of this paper was to demonstrate whetherdiureticshould be continued on hemodialysis patients with some residual diuresis, even after they have been on dialysis for a period of time.For the specifichemodialysis population, adose of furosemide, can significantly improve echo parameters, it reduces the weight gainbetween dialysis, may result in better blood pressure values and possible lower the risk of heart failure and improved symptoms. Furthermore, there may be a favorable impacton cardiac hemodynamics, probably both by vascular and renal effects.

\section{References}

1.LAMARCHE C,PICHETTE M,OUIMET D,VALLÉE M,BELL R,OUELLET G,STEWART J AND PICHETTE V. Pharmacokinetic and Dynamic of Furosemide in Peritoneal Dialysis Patients.Perit Dial Int. 2016 J anFeb; 36(1): 107-108.

2.HAYASHI SY, SEEBERGER A,LIND B,GUNNES S, ALVESTRAND A, MAZZA DO NASCIMENTO M, LINDHOLM B AND BRODIN LA.Acute effects of low and high intravenous doses of furosemide on myocardial function in anuric haemodialysis patients: a tissue Doppler study. Nephrol Dial Transplant (2008) 23: 1355-1361.

3.MEDCALF JF, HARRIS KP, WALLSJ. Role of diuretics in the preservation of residual renal function in patients on continuous ambulatory peritoneal dialysis.Kidney Int. 2001 Mar;59(3):1128-33.

4.KJAERGAARD KD, JENSEN JD, PETERS CD AND JESPERSEN B. Preserving residual renal function in dialysis patients: an update on evidence to assist clinical decision making. NDT Plus. 2011 Aug; 4(4): 225-230.

5.GREEN D, KALRA RP, KALRA PA. Echocardiographic abnormalities in dialysis patients with normal ejection fraction. Nephrol Dial Transplant (2012) 27: 4256-4259

6.SILBERBERG JS, BARRE PE, PRICHARD SS ET AL. Impact of left ventricular hypertrophy on survival in end stage renal disease. Kidney Int(1989); 36:286-289

7.MOSTOVAYA IM, BOTSML, A. VAN DEN DORPEL M,GOLDSCHMEDING R, H. DEN HOEDT C, KAMP O,LEVESQUE R, MAZAIRAC AHA,PENNE EL, SWINKELS DW, C. VAN DER WEERD N, WEE PM,NUBÉMJ, BLANKESTIJN PJ,AND GROOTEMAN MPC. Left Ventricular Mass in Dialysis Patients, Determinants and Relation with Outcome. Results from the COnvective TRansport STudy (CONTRAST). PLoS One. 2014; 9(2): e84587.

8.LANG RM, BADANO LP, MOR-AVI V, ARMSTRONG A ET AL. Recommendations for Cardiac Chamber Quantification by Echocardiography in Adults: An Update from the American Society of Echocardiography and the European Association of Cardiovascular Imaging. J ournal of the American Society of Echocardiography, Volume 28, Number 1.

9.NAGUEH SF, SMISETH OA, APPLETON CP ET AL. Recommendations for the Evaluation of Left Ventricular Diastolic Function by Echocardiography: An Update from the American Society of Echocardiography and the European Association of Cardiovascular Imaging. J Am SocEchocardiogr 2016;29:277-314.

10.NAGUEH SF, BHATT R, VIVO RP, KRIM SR,SARVARI SI,RUSSELL K, EDVARDSEN T, SMISETH OA, ESTEP JD. Echocardiographic Evaluation of Hemodynamics in Patients With Decompensated Systolic Heart Failure.Circ Cardiovasc Imaging.2011;4:220-227.doi: 10.1161/ circimaging. 111.963496
11.BIE MK, MARSAN NA, GAASBEK A, BAX JJ,GROENEVELD M, GABREELS BA,DELGADO V,RABELINK TJ,SCHALIJ MJ, AND JUKEMA JW. Left Ventricular Diastolic Dysfunction in Dialysis Patients Assessed by Novel Speckle Tracking Strain Rate Analysis: Prevalence and Determinants.Int J Nephrol.2012; 2012: 963504.

12.NAGUEH SF, MIDDLETON KJ , KOPELEN HA, ZOGHBI WA, QUINONES MA. Doppler tissue imaging: a noninvasive technique for evaluation of left ventricular relaxation and estimation of filling pressures. J Am CollCardiol 1997;30:1527-1533.

13.MILLER LM,HOPMAN WM,GARLAND JS,YEATES KE AND PILKEY RM. Cardioprotective medication use in hemodialysis patients. Can J Cardiol. 2006 J ul; 22(9): 755-760.

14.IVAN, M.V., GEORGESCU, M., APOSTOL, A., ALBULESCU, N., SERB, A.F., TATU, C.S.,Trimetazidine, a metabolic modulator, with cardioprotective effects against myocardial ischemia; Rev.Chim. (Bucharest) 69 no 7, 2018 p.1616.

15.MUNTEANU, M., APOSTOL, A., IVAN, M.V.., New Considerations Regarding Chronic Kidney Disease, Cardiovascular Disease and Dyslipidemia in Diabetic Patients. Rev. Chim. (Bucharest), 69 no 8, 2018, p. 2064.

16.IVAN MV, ROGOBETE A, BEDREAG O ET AL - New Molecular and EpigenicExpression as Novel Biomarkers in Critically III PolytraumaPatients with Acute Kidney Injury (AKI) - Clinical Laboratory, volume:64 Issue:5, pg 663-668.

17.ROGOBETE AF, SANDESC D, BEDREAG OH, PAPURICA M, POPOVICI SE, BRATU T, POPOIU CM, NITU R, DRAGOMIR T, AABED HIM, IVAN MV. MicroRNA Expression is Associated with Sepsis Disorders in Critically III Polytrauma Patients. Cells. 2018;7(12):271. Published 2018 Dec 13.

18.GONZALEZ VILCHEZ F ET AL. Comparison of Doppler echocardiography, color M-mode Doppler, and Doppler tissue imaging for the estimation of pulmonary capillary wedge pressure. J Am SocEchocardiogr 2002; 15: 1245-1255.

19.MUKHERJ EE SK ET AL. Mechanisms of hemodynamic actions of furosemide: differentiation of vascular and renal effects on blood pressure in functionally anephric hypertensive patients. Am Heart J 1981; 101: 313-317

20.SCHMIEDER RE, MESSERLI FH, DECARVALHO JG. Immediate hemodynamic response to furosemide in patients undergoing chronic hemodialysis. Am J Kidney Dis 1987; 9: 55-59.

21.GADALEAN F, SIMU M,PARV F,VOROVENCI R, TUDOR R, SCHILLER A, TIMAR R, PETRICA L,VELCIOV S, GLUHOVSCHI C, BOB F, MIHAESCU A, TIMAR B, SPASOVSKI G,IVAN V (2017). The impact of acute kidney injury on in-hospital mortality in acute ischemic stroke patients undergoing intravenous thrombolysis. PLOS ONE Volume:12 Issuue:10 Article number:e0185589 Published:OCT 172017

22.IVAN, M.V, PETRE, I, VLAICU, B, APOSTOL, A, TESLOIANU, D, MUNTEANU, M, COSTACHESCU, R, MOLERIU, L.C, LAZAR, F.,The Use of Pulse Wave Velocity in Predicting Pre-Eclampsia in High-Risk Women Rev. Chim. (Bucharest), 69 no. 5, 2018 p. 1260-1263.

23.POWE NR, FINK NE. The CHOICE Study: A National Study of dialysis outcomes in the United States. Nefrologia Vol. 19. Num. S1.February 1999pages 0-90.

$\overline{\text { Manuscript received:22.08.2018 }}$ 